\title{
NOTAS SOBRE LA ECONOMÍA FRONTERIZA CASTELLANO-ARAGONESA EN LA BAJA EDAD MEDIA
}

\author{
FRANCISCO DE MOXÓ Y MONTOLIU \\ Centro de Estudios Universitarios (Madrid)
}

Una de las zonas peninsulares en donde la huella del Medievo ofrece mayor interés es sin duda la que constituyó la frontera entre Aragón y Castilla: desde el punto de encuentro de ambos reinos con Navarra, al norte de Agreda, hasta las costas mediterráneas entre Murcia y Alicante. Zona cuyos límites se fueron fijando laboriosamente por diversos tratados al compás del avance reconquistador de ambos reinos, pero pese a ello nunca plenamente definidos (1), y sometida a fuertes tensiones de una y otra parte que la hicieron escenario de la aparición de importantes estados «tapón» de tipo señorial como Molina de Aragón, Albarracín y Villena, de una comarca castellana con denominación tan curiosa como la "Mancha de Montearagón" o de una «isla" aragonesa en territorio castellano como fue calificado el señorío de Caudete (2).

Sin pretender abarcar aquí toda la amplia problemática de la zona, y supuestas las peculiaridades de cada sector de la misma, ya bien estudiadas por diversos autores (3), creemos que es posible hablar de algunos aspectos económicos comunes a los que dicha situación fronteriza diera lugar. Si es evidete que esa particular posición política de tránsito, con una cierta como «ósmosis» de personas y mercancias en una u otra dirección, favoreció su prosperidad económica, no lo es menos que los no infrecuentes momentos de conflictividad bélica, con las devastaciones y rapiñas consiguientes, entorpecieron constantemente su desarrollo.

Vamos a verlo con más detención apoyados en los datos que nos suministra la historiografía y aportando al mismo tiempo alguna nueva luz documental. 


\section{LA GANADERIA: FACILIDADES Y PREVENCIONES}

La zona fronteriza coincidentre con el Sistema Ibérico hasta sus últimas estribaciones meridionales era eminentemente ganadera y maderera. Ya M. Colmeiro en su «Historia de la Economía Política en España» observaba que «en la corona de Aragón abundaban los pastos y había partidos enteros, como el de Albarracín, cuya riqueza consistía casi exclusivamente en ganados. Los de Zaragoza y otras partes del reino iban a herbajar a esta comunidad o pasaban la frontera, dirigiéndose a Valencia, Murcia y Andalucía. La finura de las lanas de Albarracín se debía al cuidado de los naturales, que procuraron mejorar las castas, cruzándolas con las de Soria y otras partes de Castillaw (4). S. de Moxó, tratando de las posesiones de los Albornoz en Moya y Valdemeca, a las que se agregarían luego Beteta y Tragacete y otras poblaciones próximas a la frontera, recuerda que «el bosque y la ganadería constituían en el S. XIV —como hoy mismo- sus principales bases económicas; observando más tarde su relación con la tierra aragonesa colindante de Albarracín «cuya riqueza en ganados era proverbial y los cuales acostumbraban a cruzarse con los de las comarcas fronterizas de Castilla -como la conquense- con beneficio mutuo» (5).

Es interesante el caso del señorío de Villena, ganadera y cerealista, que, adjudicado en Torrellas (1304, en cuanto a la jurisdicción al rey de Aragón, si bien la propiedad quedaba para don Juan Manuel (6), acabó decantándose otra vez plenamente del lado castellano (7). El 10 de enero de 1340, se-

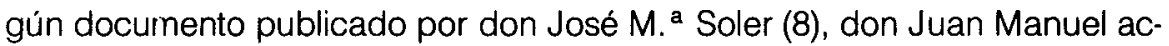
cedía desde Madrid a la petición de los habitantes de Villena «en razón de las cosas de vuestra criança e de vuestra cogida, que me pediades por merced que lo pudiesedes sacar a Aragón para vos aprovechar dello, et que non pagasedes diezmo ninguno pues erades de la conquista de Aragón»; pero dejando bien claro «que todos aquellos vuestros vezinos que quisieren sacar ganado de Castiella por Villena o a Aragón que paguen sus derechos».

No se mostró igualmente favorable Juan I en 1382 cuando los de Murcia, citando el privilegio anterior, le enviaron «a pedir por merced que os la ficiesemos de poder sacar para Aragón el pan que toviesedes de vuestra labranza, e los ganados que oviesedes de vuestra crianza, segund que se solía usar, e segund que lo sacan los de Villena, por el privilegio que de ello tienen». El rey les contestaba que «por agora non es nuestra merced de os dar esta saca, por la megua de ganados que hay en esa tierra por la pestilencia e mortandad que en ellos ha habido este años (9).

Esta actitud restrictiva no era nueva en el S. XIV. Ya en 1330 Alfonso IV de Aragć $:$ se quejaba a Alfonso XI de la prohibición de sacar «ganado groso 
o menudo» del reino de Castilla, lo cual — decía - «es en daño del reino de Valencia y no lo acostumbraron sus predecesores» (10); y al mes siguiente rogaba al rey castellano no escuchase a los que acusaban a Pedro Ruiz de Azagra de haber sacado ilegalmente caballos de Castilla (11). Años más tarde, después de la época conflictiva del reinado de Pedro el Cruel, pero antes de la paz definitiva de 1375 entre Aragón y Castilla, era Enrique Il quien renovaba esa actitud en las Cortes de Medina del Campo de 1370 y nombraba un alcalde comisario para el comercio entre ambos reinos; pese a lo cual, como observa Valdeón, se siguió produciendo la salida de mercancías prohibidas, como el ganado y viandas en general, de Castilla a Aragón (12).

\section{EL TRASFONDO MONETARIO}

En el fondo estaba la cuestión monetaria y la mayor prosperidad económica de Aragón que, patente en la primera mitad del XIV, culminó en la creación del florín de oro por Pedro IV en 1346 y se mantuvo sustancialmente pese a las sucesivas devaluaciones del mismo, índice de una progresiva decadencia, en la segunda mitad de la centuria (13).

A ello se añadió la circunstancia, que recoge la Crónica de Alfonso XI, de no haberse labrado moneda en Castilla durante la minoría y primeros años del reinado de dicho monarca, y por ello uera muy apocada la moneda que mandara labrar el rey don Fernando su padre, et por esto en todas las villas de la frontera de Aragón et en todo el arzobispado de Toledo corría la moneda del rey de Aragón en esta guisa: los dineros jaqueses en prescio de coronados et los dineros reales en prescio de dineros novenes», cosa que sucedía también en otras fronteras de Castilla, por lo cual el rey ordenó que se volviese a labrar moneda de la misma ley y talla (14).

Por su parte Jaime II, en 1323, no habia accedido a la petición de don Juan Manuel de acuñar moneda propia en Villena (15). Pese a ello, pocos años después (1331), la Crónica de Alfonso XI nos informa de que don Juan Manuel hacía labrar coronados en Cañevate, añadiendo la interesante observación de que, para traer plata «facía levar fuera del regno muchos ganados e mucho pan e muchas mercaderías...» (16). La misma pretensión de acuñar moneda-privilegio que acompañaba al título ducal-subyace a la insistencia de don Juan Manuel por obtener el mismo, sea de Alfonso XI de Castilla (17) sea de los reyes de Aragón Alfonso IV y Pedro IV. Estos últimos, al concederle el título ya de príncipe ya de duque, excluyeron sin embargo expresamente dicha facultad (18).

En 1371, poco después de las Cortes de Medina del Campo de que an-

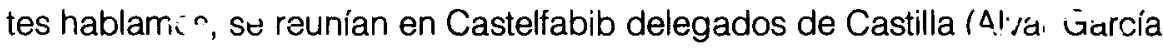


de Albornoz uno de ellos) y de Aragón para tratar de llegar a un acuerdo por mediación del Legado Pontificio. Y, entre otras instrucciones, los embajadores aragoneses llevaban la de decir que cesaría la acuñación de moneda castellana en Aragón «a cambio de detenerse la acuñación de florines aragoneses en Castilla» (19). Aunque de este dato no podamos deducir una superioridad de la moneda aragonesa, sí es significativo que el mismo año, al comprar el Infantado al marqués de Villena, los Albornoz lo pagasen - «a modo de divisa internacional» en expresión de S. de Moxó (20)- en 30.000 florines de Aragón (21). Y aún lo es más el que, al llegarse en 1375 a las paces de Soria entre Aragón y Castilla, se fijasen preferentemente tanto la dote de Leonor de Aragón en su boda con el infante Juan (compensada con la misma cantidad entregada a Enrique de Trastámara cuando su lucha por el trono) como la reparación de éste a Pedro IV por los gastos hechos en favor de su causa, en florines de oro de Aragón (22).

El aprecio de la moneda aragonesa se manifestaba todavía en tiempo de Juan I cuando los habitantes de Murcia, en la petición de 1382 que antes mencionamos, aducian para apoyärla la razón de ser «más ricos en moneda» al poder sacar a Aragón sus mercancías (23).

\section{MADERA PARA EL ESTRECHO}

Hemos dicho que la riqueza de buena parte de esa zona fronteriza, en el sector coincidente con el Sistema Ibérico, era no sólo ganadera sino también forestal. Impresiona todavía hoy recorrer los magníficos pinares que se extienden desde Cañete hasta Moya o de Tragacete a Valdemeca y hasta la sierra de Albarracín. Tenemos constancia documental de cómo la madera de la zona limítrofe castellana era llevada, no sin dificultades e impedimentos a veces, Guadalaviar abajo hasta Valencia, de donde en ocasiones era enviada al Sur de la Península para cubrir las necesidades de las plazas del Estrecho.

En el Archivo de la Corona de Aragón hemos encontrado un interesante documento consistente en una carta de Alfonso XI, que ya empezaba a planear su nueva acción sobre Gibraltar, escrita el 20 de enero de 1347 a Pedro IV protestando del embargo realizado a mercaderes de Moya que llevaban madera a Valencia (24). Pocos días después (7 de febrero) Pedro IV comunicaba a su vez a Alfonso XI que, dada la reciente sequía, no podía permitir al despensero de don Juan Manuel transportar por el rio Guadalaviar «la fusta quel dito $D$. Johan de vuestro mandamiento ha feyto tallar en los montes de Moya por bastecer la vuestra ciudad de Algezira» sin que pague el derecho equivalente al de los regantes perjudicados (25). Seguramente, vencidas 
las dificultades, esa madera llegaría por fin a Algeciras, como lo sugiere la relación de estos textos con el del capítulo 273 de la Crónica de Alfonso XI, por más que este último se refiera al anterior cerco de Algeciras en 1342:

«Et porque los de la hueste oviesen madera para facer casas, envió mandar el rey que de los pinares de Moya traxiesen madera a Valencia, que es en Aragón, et dende la traían por la mar fasta Algecira: et fallaron los omes en esto grand ayuda para facer moradas, ca las tiendas todas eran rotas con el fuerte tiempo que les avia fecho: et algunos dellos traían fechas las casas de la madera, que non avian de facer al, si non asentarlas»(26).

Añade la Crónica que también de Vizcaya trajo por mar mucha madera don Juan Núñez de Lara; y menciona en capítulos sucesivos «bastidas de madera» (c. 275), «una bastida de madera alta en guisa de torre» (c. 279), «tablas et cuentos de madera» en la cava o trinchera (c. 289) y «un castiello muy alto... et muy sotil» (c. 290).

\section{ROBOS Y «PENDRAS»}

No era raro, aun en tiempos de paz entre Aragón y Castilla que con cierta frecuencia se produjesen robos y daños a una y otra parte de la frontera, que los respectivos monarcas trataban de remediar (27). A este respecto es interesante la carta de Jaime II en 1314 a Ramón de Avinyó, vicario general tarraconense «super facto peccunie et aliarum rerum subrreptarum infra regnum Aragonie per quosdam de regno Castelle, que erant archiepiscopi prelibati». A la propuesta que le hiciera el vicario de resarcirse con bienes castellanos contesta el rey que prefiere utilizar la vía diplomática, ya que «terrarum nostrarum conamur, quantum possumus, frontarias tenere quietas» (28). Otra vez es Alfonso XI quien pide a Alfonso IV (1331) corrija los abusos de súbditos suyos que roban en el señorío de Molina y pasan la frontera para vender lo robado en Aragón (29).

Estos robos eran a veces remediados directamente por los habitantes de uno y otro lado de la frontera por el sistema de «pendras" (prendas) o compensación consistente en embargar bienes de habitantes del reino vecino en tanto no se hubiese devuelto lo robado o satisfecho en justicia; lo cual daba lugar a nuevas reyertas y altercados que más que arreglar, empeoraban la situación. Se prefirió pues la vía del convenio o de la amigable composición.

Ya en 1262 se registran acuerdos particulares entre las hermandades de Teruel y Molina para remediar, entre otros, los asuntos de robos (30). En 1286 los reyes de Castilla y Aragón nombraban respectivamente a Sancho Martí- 
nez de Luna y Lope Ferrench de Luna para evaluar y enmendar los daños mutuos ocasionados entre hombres de Aragón y Castilla (31). En las vistas de Tarazona de 1329 celebradas con ocasión del enlace matrimonial de Alfonso IV con Leonor de Castilla, hermana de Alfonso XI, trataron ambos reyes de resolver esas querellas fronterizas por mutuas injurias entre particulares sin llegar a una solución evectiva, como lo manifiesta la correspondencia entre ambos monarcas en 1331 en la que se propone nombrar personas de uno y otro reino para acabar con el problema (32). En 1332 Alfonso IV declaraba que la imposición de una multa de 2 dineros por libra no había resultado y proponía de nuevo se buscase una resolución defintiva del asunto (33). Todavía en el verano de 1335 se registra un intercambio de correspondencia entre Alfonso XI y Alfonso IV, a propósito de hechos acaecidos en las comarcas de Medinaceli, Molina y Daroca, que termina con la prohibición de las «pendras» por parte de Alfonso IV y la propuesta a su cuñado el rey de Castilia de enviar dos delegados, uno por cada reino, a la comarca de Molina para resolver en justicia (34). La muerte del Benigno a principios del año siguiente daría fin a tan bienintencionados tratos sin haber seguramente resuelto el endémico problema.

\section{DEVASTACIONES BÉLICAS}

Sin embargo los momentos más graves para las poblaciones fronterizas fueron los de las confrontaciones bélicas entre los dos Estados, o entre ambos y los señorios limitrofes, que las afectaron de un modo particularmente negativo. Así sabemos por ejemplo del daño "grande» que hizo en 1284, don Juan Núñez de Lara en las comarcas de Teruel desde Albarracín (35). Poco después, en 1289, la Crónica de Sancho IV nos relata la entrada de este rey por Agreda hasta Tarazona, desde donde «fizo fazer muy cruda guerra en el reino de Aragón, matando, robando, quemando, cortando las olivas e los árboles e poniendo fuego a toda la tierra» hasta la ribera del Ebro (36). Aún a tiempo de tregua en la guerra Aragón-Castilla, en 1296, se quejaba Jaime Il al merino mayor de don Juan Manuel «contra la rapiña de algunos de sus hombres al asaltar a ciertos vecinos de Murcia (recién ocupada por el aragonés) que transitaban por sus tierras con bestias cargadas de trigo, escanda, granos, paños y otras mercancías, sin atender a que, en virtud de la tregua vigente, unos y otros debían disfrutar de seguridad en sus movimientos» (37).

Conflicto particularmente devastador fue el iniciado en 1356, de cuyas repercusiones fronterizas se ocupó ampliamente hace unos años $A$. Gutiérrez de Velasco por lo que nos limitaremos a exponer algunos ejemplos (38). La guerra fue dura desde sus inicios en que se registran ya mutuas invasio- 
nes. Zurita consigna que «los de Molina entraron en Aragón corriendo y talando los lugares y aldeas de Daroca, y quemaron dos que se dicen Ojos Negros y Blancas». Más al Sur, por obra de los aragoneses «se quemaron más de 50 aldeas y el arrabal de Requena» (39). Al año siguiente (1357) Pedro I entraba en Aragón talando y destruyendo los campos de Calatayud y Daroca (40).

De los efectos demográficos del conflicto con la destrucción de poblaciones y el trasiego de los habitantes pueden darnos idea las instrucciones dadas por el rey de Aragón. Disponía que si llegaban los enemigos a Munébrega (como sucedió) «se pegase fuego a la villa fuera del cortijo» y lo mismo se hiciese en Bubierca; que los habitantes de Santet pasasen a Jaraba; que se despoblase Brijuesca; que los hombres de Ateca se refugiasen en lbdes y las mujeres y niños en Calatayud, en donde habian de reunirse también los habitantes de Santos, Sabiñán, Paracuellos y Morata. Se despobló la villa de Alhama, cuyos habitantes subieron al castillo, y asimismo se despoblaron Cervera, Añón y la mitad de Torijo, etc. (41)

La guerra se prolongó como es sabido, aun después de terminada la guerra civil castellana en 1369, hasta 1375, época en que Molina, Cañete y Moya se pasaron a la obediencia del rey de Aragón (42). En Aragón se recogieron los ganados y se sacaron de las fronteras (43); y Pedro IV ordenó al gobernador de Aragón hiciese segar los «panes» (trigales) y llevarlo todo a las fortalezas (44). En 1374 serían el conde de Medinaceli y otros castellanos quienes penetrasen devastando por la comarca de Molina (45). $Y$ al firmarse la paz en 1375 con la devolución de Molina a Castilla se ofreció a los vecinos de esta villa que lo deseasen la posibilidad de irse a Aragón (46).

No sólo la invasión extranjera sino también el mantenimiento del propio ejército y las requisas y desmanes de las guarniciones dañaban la economía de las poblaciones fronterizas. Hubo quejas de que los capitanes se habían apoderado sin pagar nada de las provisiones reunidas en los castillos de Ateca, Alhama y Bubierca; y Pedro IV hubo de atender a la reclamación de los hombres buenos de las aldeas de Calatayud sobre la devolución del ganado que el gobernador de Aragón les mandara requisar. En Ariza los capitanes de la guarnición se apoderaron de 6.790 ss. que se negaban a devolver, por lo que el rey mandó que se descontasen de sus pagas (47).

No menos perjudiciales fueron las contiendas castellano-aragonesas del s. XV. En 1429 Juan II de Castilla "embió mandar a todas las villas de las fronteras que hiciesen guerra cruel en los reynos de Aragón e Navarra» cuyo resultado fueión jrandes daños e talas e quemas" (48). Poco después el pro- 
pio rey, acompañado del condestable D. Alvaro de Luna, entraba en Aragón por Ariza, que era la primera villa pasada la frontera; ante lo cual «se despoblaron todos los lugares de la frontera que no eran defendederos» «e la mayor parte de la villa fue quemada» (49). Rehecha, de nuevo en 1475 sufriría el ataque del conde de Medinaceli (en guerra con el señor de Ariza), cuyos hombres talaron la vega y quebraron los molinos (50). No tardó en reaccionar Alfonso $V$ quien, partiendo de Calatayud, tomó a Deza por sorpresa llevándose a moros y cristianos; y aunque a éstos los soltó luego, fue con la condición de que no volviesen a Deza. La villa fue saqueada «haciendo mucho mal e daño; e créese que llevó más de diez mil cargas de trigo y cevada, e muchos muebles e ganados de los vecinos de aquella tierra" (51).

Años después, en 1447, las turbulencias del infante D. Juan, rey de $\mathrm{Na}$ varra, que acabaron arrastrando consigo a Aragón, devastaban los pueblos de una y otra parte de la frontera. Avanzando por tierras de Soria «los robos que los del rey de Navarra hacian destas fortalezas todo lo llevaron a vender al reyno de Aragón e eran allí acogidos»; por lo cual el alcaide de Peña del Alcázar tomó «la fortaleza de Verdejo que es en el reyno de Aragón, frontero de Castilla», con lo que atajó "el paso de los robos que se hacian desde Atienza e los traian a vender al reyno de Aragón» (52).

Otros puntos fronterizos más al sur fueron pronto afectados. En 1449 los castellanos de Molina intentaron robar los ganados de Cutanda, Rubielos, Cossa y Bañón. D. Juan de Luna, capitán general de las fronteras de Daroca, hubo de poner gente de guerra en Torralba de los Frailes, muy próximo a la frontera, desamparado por su población (53). Y en el mismo año entraban por Requena y Utiel en Castilla «gente del reino de Aragón, que serían docientos de caballo e quiñientos peones... e robaron ende hasta doce mil cabezas de ganado menor» (54); dato que, de paso, nos confirma cuanto dijimos anteriormente de la riqueza ganadera de la zona.

Balance de los efectos de esos años de confrontaciones bélicas es el resumen de la situación que la embajada aragonesa a Nápoles, en 1452, exponía a Alfonso $V$ reclamando su presencia: «Grandes despoblaciones de lugares en las fronteras, señaladamente en tierra de Teruel y Albarracín y en las comarcas de Daroca, Calatayud y Aranda, y ya no se labraban ni cultivaban las tierras: y no solamente se había seguido este estrago de los enemigos, pero de la gente de armas que estaban en servicio del rey de Navarra y de los que residian en las guarniciones... y se les sufrian sus insultos y robos porque no recibían gajes ni sueldo alguno». Además se habia gastado «en res- 
cates de prisioneros cuatrocientos mil florines" y había cesado «el trato y comercio de Castilla y Navarra" (55).

Asi afrontaba esa zona singular del territorio hispano el tránsito a la Edad Moderna, que llevaría aparejado el fin de su condición fronteriza, bien que durante la época de los Austrias y aún hasta la posterior extinción de los señoríos en el s. XIX conservase alguna que otra de las características del pasado. La división provincial de 1833 alteró un tanto la antigua línea fronteriza, llevando a las poblaciones de Utiel, Requena y Villena (1836) a integrarse en la región valenciana pese a su secular adscripción a Castilla. Pero, cualquiera que fuese el resultado final, sí podemos afirmar como conclusión de todo lo dicho que, al salir del Medievo, la riqueza pecuario-forestal y la posición comercial privilegiada de la zona se habian visto ampliamente contrarrestada por el efecto negativo de las confrontaciones bélicas a las que su situación la hiciera particularmente sensible. De ahí que, al perder su carácter fronterizo, esas comarcas interiores quedaran afectadas $-y$ tanto más cuanto más interiores, más alejadas de las vias modernas de comunicación y más enriscadas en el Sistema Ibérico- de un cierto adormecimiento letárgico que ha penetrado su vida urbana hasta nuestros días. Muchas lo han ido superando con meritorio esfuerzo: en todo caso creemos que los estudios consagrados en nuestros días a la reavivación de la conciencia de su identidad histórica habrán de contribuir a preparar a las mismas un más próspero futuro. 


\title{
APÉNDICE DOCUMENTAL
}

\author{
1347, enero, 20. Villa Real.
}

Alfonso $X I$ ruega a Pedro $N$ mande se resuelv en justicia el asunto de unos mercaderes de Moya que llevaban madera a Valencia y se les embargó.

ACA, CR, Pedro IV 4556

Al much alto e muy noble Don Pedro, por la gracia de Dios rey de Aragón et de Valencia et de Mallorca et de $1 /$ Córcega et de Sardenia et de Rosellón et de Ceritania et conde de Barcelona. Don Alfonso, por esa misma gracia rey $2 /$ de Castiella, de Toledo, de León, de Gallisia, de Sevilla, de Córdova, de Murcia, de Jahen, del Algarbe, de Algesira et sennor de 3/ Molina. Salud como a rey que mucho amamos et que mucho preciamos et para quien querriemos tanta vida et salut como para 4/ Nos mismo. Rey, fasemos vos saber que algunos nuestros vasallos mercadores et otros omes viandantes de la villa de Moya et de 5/ otros logares de nuestro sennorío se nos querellaron et disen que ellos que an cartas vuestras de los reyes de Aragón onde Vos venides de 6/ seguramiento et de guiajes que vayan salvos e seguros con todas las sus cosas et mercadurias asi madera como otras cosas quales7/ quier que levaren a la cibdat de Valencia et a qualesquier otras villas et logares del vuestro sennorío; et que no sean prendados ni marcados ni embargados ellos ni las sus mercadurías. Et que aviendo ellos levado fusta a la dicha cibdat de Valençia et a otras partes de 9/ su regnado, que algunos ofiçiales et otras personas de Valençia et de otras partes de vuestro sennorio, que les an tomado et embargado la 10/ dicha su madera sin razón ni derecho por algunos fechos estrannos a que ellos non son tennidos ni obligados. Et en esto que reçiben 11/ grandes agravios et que pierden mucho de lo que an por mengua de derecho, non les guardando las cartas de 'os quia'jes et 
segura-12/ miento que ellos diz que an de Vos et de los reyes onde Vos venides en esta razón, ni les guardando el fuero de la dicha cibdat 13/ de Valençia que an los mercaderes et todos los otros omes viandantes que y fueren con sus mercadurías. Et que comoquier que por muchas $14 /$ veses an requerido e afrontado a los ofiçiales de la dicha cibdat de Valençia et a los vuestros comisarios que por estos fechos libra-15/ diestes en que les fisiesen guardar et mantener las dichas vuestras cartas et de los dichos reyes de seguramiento et guiages que 16/ tienen ellos en esta razón, que lo non quisieron nin quieren facer, nin pueden ende aver complimiento de derecho. Et pidieron nos merced $17 /$ que les madasemos dar nuestra carta para Vos sobresta razón. Por que vos rogamos, rey, que tengades por bien de enbiar 18/ mandar a los ofiçiales de la çibdat de Valencia et a los vuestros comisarios que para librar estos fechos avedes dado, et que vean 19/ las cartas de seguramiento et de guiages que los nuestros vasallos tienen de Vos et de los reyes onde Vos venides en esta razón como 20 / dicho es. Et que gelas guarden et façan guardar segund que en ellas se contiene. Et si alguna madera o qualquier otra mercaduria les $21 /$ an tomado o tienen embargado, que gela fagan dar et desembargar. Et esto tened por bien de lo mandar así complir et guardar. Et 22/ de derecho a los de la vuestra tierra que alguna querella 23/ oviesen de los de la nuestra. Et desí quitaredes prendas et dannos dentre las vuestras gentes et las nuestras. Dada en Vila 24/ Real, veynt dias de enero era de mill et tresientos et ochenta et cinco annos (Signo) Yo Johan Ferrandis lo 25/ fis escrivir por mandado del rey (Signos). 


\section{NOTAS}

(1) E. MITRE, en una valiosa monografía dedicada a la delicada situación a que se llegó en tiempo de Enrique II al ostentar D. Alfonso de Aragón la titularidad del Marquesado de Villena, ha podido hablar de una «amplia difuminación de los límites» entre los dos grandes estados peninsulares "Señorío y frontera (El Marquesado de Villena entre 1386 y 1402)» en uMurgetana», vol. XXX, Murcia 1969. Prescindimos en este análisis de la zona fronteriza más próxima al Mediterráneo, entre las actuales provincias de Murcia y Alicante, estudiada ya en notables trabajos por los Dres. Torres Fontes y Del Estal y a la que ha dedicado recientemente su Tesis doctoral la Srta. M. a TERESA FERRER I MALLOL: «Moros i cristians, almogàvers i collerats à la frontera d'Oriols (s. XIV)" (Univ. Barc. 1984)

(2) «Insula Valentiae in Castellae regione" (Mapa de Abraham Ortelio de 1584; cf. J. M. ${ }^{a}$ SOLER «Historia de Villena» págs. 97 y 140). Sobre la Mancha de Montearagón (zona de Chinchilla) ver Crón. de Pedro I, cap. LXVI, nota 4 de la ed. «Bibl. de autores españoles" $t$. LXVI, págs. 420-421; Crón. Enrique II, $4^{\circ}$ año, cap. II, ibidem t. LXVIII, pág. 2; así como la Comunicación de A. PETREL al Congreso de H. ${ }^{\text {a }}$ de Albacete de 1983 (ed. 1984, II, págs. 263-271): «En torno al concepto y límites de un topónimo olvidado: la Mancha de Montearagón».

(3) S. CARRERES ZACARÉS «Tratados entre Castilla y Aragón. Su influencia en la terminación de la reconquista" (Tesis doctoral) Valencia 1908; R. CHABÁS «División de la conquista de la España mora entre Aragón y Castilla» (I Congr. de H. ${ }^{a}$ de la C. de Aragón 1908, t. I, págs. 139-141); J. TORRES FONTES «Las delimitaciones del Sudeste peninsular. Torrellas-Elche 13041305» en "Arales de la Univ. de Murcia 1950; "La conquista del Marquesado de Villena en el reinado de los RR. Católicos" en «Hispania» $L$ (1953); “La Hermandad del Marquesado de Villena en 1386» en «Villena» 23, Alicante 1973; J. M. DEL ESTAL «Conquista y anexión de Alicante al reino de Valencia» en «Rev. del Instituto de EE. Alicantinos», 15 (1975), págs. 127-158; «Problema sucesorio de Castilla y anexión de Alicante a la C. de Aragón», VII Centenario del Inf. D. Fdo. de la Cerda (1975), Ciudad Real 1976, págs. 237-263; «Las tierras levantinas de Albacete en la dinámica expansionista de Castilla y Aragón en los dos tercios últimos del $\mathrm{s}$. XIII e inicios del XIV , Congreso de Historia de Albacete, II Edad Media, Albacete, 1984, pp. 49-79; "Historia política de Alicante en la Edad Media (1238/1243-1479)", Historia de la Provincia de Alicante II, Alicante 1985, pp. 169-286; "Vaivén político del Señorio de Villena entre Castilla y Aragón (siglos XIII y XIV)» Congreso de Historia del Señorío de Villena, Albacete 23-26 octubre 1986 (en prensa); A. GIMÉNEZ SOLER «Don Juan Manuel. Biografía y estudio crítico» Zaragoza 1932; J. M. " SOLER GARCIA «Historia de Villena" (publ. en fascículos del Dep. de Cultura del Ayuntamiento de Villena). M. ALMAGRO BASCH «Historia de Albarracín y su sierra t. III y IV, Teruel 1959-1964; Catálogo de los Archivos Municipales Turolenses (IV vols.), Ins. de EE. Turolenses 1982-1985. J. SANZ DIAZ «H. a verdadera del Señorío de Molina», Guadalajara 1982; M. ROMERO SAIZ “Cañete, Historia y Leyenda», Cuenca 1978; J. GONZÁLEZ «Repoblación 
de las tierras de Cuenca», AEM 12 (1982), págs. 183-204; M. a EMMA ESPOILLE DE ROIZ «Repoblación de Cuenca (ss. XIII-XVI)», AEM 12 (1982), págs. 205-239; A. PETREL MARÍN «Conquista y primeros intentos de repoblación del territorio albacetense", IEA, Albacete, 1986; “Don Juan Manuel, Señor de la llanura», IEA Albacete, 1982; J. L. PASTOR ZAPATA «Un ejemplo de apanage hispánico: el señorío de Villena (1250-1445)», en «Rev. Inst. de EE. Alicantinos» 31 (1980), págs. 15-40. En el Congreso de $H_{\text {. }}{ }^{\text {a }}$ de Albacete de 1983 se presentaron otros valiosos trabajos de índole económica (F. A. VEAS, M. RODRIGUEZ LLOPIS, etc.), cuya mención omitimos por no hacer propiamente referencia a la relación fronteriza con la Corona de Aragón.

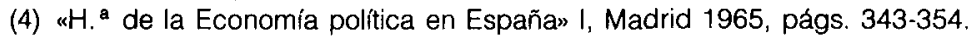

(5) «Los Albornoz. La elevación de un linaje y su expansión dominical en el siglo XIV» en «Studia albornotiana» vol. XI, 1972, págs. 34 y 43. A ello hay que añadir en algunas villas el intenso tráfico comercial y aduanero que la situación geográfica favorecía. M. ROMERO (o. c. pág. 55) recuerda como Cañete tenía un gran mercado. Ver también la Memoria de Licenciatura de MARÍA DEL CARMEN GARCIA HERRERO «Aportaciones al estudio de las relaciones comerciales entre Aragón y Castilla. La aduana de Calatayud 1445-1446» (Univ. Complutense de. Madrid 1982)

(6) J. M. del ESTAL «Problema sucesorio...», págs. 252-253.

(7) Ello se produjo insensiblemente a lo largo del s. XIV. La Crónica de Pedro I (1360, c. XXIII, pág. 510) dice que al morir en Sevilla D. ${ }^{a}$ Blanca de Villena, nieta de D. Juan Manuel, «incó toda su tierra en el rey (D. Pedro)». Pero Enrique de Trastámara la consideró suya en virtud de los derechos de su mujer D. ${ }^{a}$ Juana Manuel y al cabo de 6 años, con solución diplomática, la dio a D. Alonso de Aragón con el título de Marqués (1366). Despojado éste, se incorporó a fines del siglo a la Corona de Castilla (cf. E. MITRE, o.C., págs. 9 y 10 , y J. M. ${ }^{a}$ SOLER o.c. págs. 106).

(8) O.c. pág. 93. El procurador de Villena recordaba este privilegio a Juan II ante la prohibición de sacar al reino de Aragón ganados y otras mercaderias (ib. pág. 135)

(9) Adiciones a la Crón. de Juan I, IV, pág. 147.

(10) ACA R. 523, f. 121 r. ${ }^{\circ}$ (Calatayud, 9 sept. 1330)

(11) ACA R. 523, f. 136 r. $^{\circ}$ (Cella, 1 oct. 1330)

(12) J. VALDEON «Enrique II de Castilla: la guerra civil y la consolidación del régimen (13661371)», Valladolid 1966, pág. 340.

(13) Las devaluaciones tuvieron lugar en 1351,1363 y 1365, llegando en este último año al $75 \%$ de su valor nominal. Sobre el estado económico de Castilla en la primera mitad del siglo ver J. VALDEON «Aspectos de la crisis castellana en la 1. a mitad del S. XIV» en «Hispania"XXIX (1969) págs. 5-24. Sobre las reformas monetarias de Enrique II ver del mismo autor: «Enrique II...» págs. 341-348.

(14) Crón. Alfonso XI, c. XCV (B. A. E., t. LXVI, pág. 230)

(15) J. M. a SOLER, o.c., pág. 88.

(16) Crón. Alfonso XI, c. XCVIII, pág. 233. Ello provocó la «creciente invasión de numerario aragonés» (J. M. a SOLER, o.c., pág. 88). El cronista manifiesta ya el olvido por parte castellana de lo establecido en Torrellas pocos años antes y considera las tierras de D. Juan Manuel como formando parte del reino castellano. El mismo D. Juan Manuel había hecho manifestar en 1310 a Jaime II que la sentencia de Torrellas era para Castilla «una espina al cor que ya mes nols exirá; e car veen que zo que don Johan a en Castella es escut del Rei d'Aragó e de sa terra entre ell e el Rei de Castella, la qua! defén de Tarasona tro a Alacant». A continuación manifestaba el disgusto también de D. Juan Núñez de Lara «per zo car lo Rei li ten Albarrasí» (G. SOLER «Don Juan Manuel»; Ap. doc. CCIX pág. 377; 18 julio 1310)

(17) Crón. Alfonso XI, c. CVII, pág. 241.

(18) Príncipe: 7 marzo 1334 (ACA R. 544 f. 98; G. SOLER, doc. DXVI, pág. 604); príncipe o duque: 15 mayo 1336 (RAH Col. Salazar A-3 f. 62 v. ${ }^{\circ}$ ) Ver también Col. Salazar A-3 f. 61 y A-4 f.9 (en G. SOLER docs. DXXXV y DXXXVIII); J. M. a SOLER págs. 89-91.

(19) ACA R. 1232 f. 118 r. ${ }^{\circ}$. ${ }^{\circ}$; Zur. An. X, 14; J. VALDEÓN «Enrique II...», pág. 267.

(20) O.c. pág. 49. 
(21) AHN, Osuna, leg. 1724 n. 9 y 1730 n. 4 y 5.

(22) 200.000 florines la primera y 180.000 la segunda. Sólo en el caso - añade Zuritade que no se hallase «tan grande cantidad de florines, se habian de dar doblas castellanas que no fuesen alfonsies, contando cada una de ellas a razón de 35 maravedis y el florín a 20; y si en doblas marroquies se hiciesen las pagas, se habrá de contar cada dobla por 32 maravedis». Dinero que se aseguraba sobre las villas fronterizas castellanas de Requena, Utiel y Moya, entregadas a representantes de Aragón (Zur. An. X, 19).

(23) Ver nota 9.

(24) ACA, CR Pedro IV 4556. Ver en nuestro Apéndice Documental.

(25) G. SOLER, o.c., doc. DLXXXI, pág. 648. El texto no parece sugerir la denegación absoluta de permiso que indica el «regesto" de G. SOLER. Don Juan Manuel, unido por estrechos lazos familiares con la corte aragonesa, sería nombrado el 24 de julio del año siguiente por Alfonso $X i$ adelantado de la Frontera musulmana y fallecería en Córdoba yendo a preparar la futura campaña de Gibraltar. Cf. nuestro trabajo «La política aragonesa de Alfonso XI y los hijos de Leonor de Guzmán», notas 34-36, en el vol. de homenaje a D. Claudio Sánchez Albornoz, «En la España Medieval» V, Univ. Complutense 1986, pág. 706.

(26) Crón. Alfonso XI, c. CCLXXIII, pág. 348. Para la relación Moya-Albornoz y la presencia de D. Gil en Gibraltar ver L. V. DÍAZ MARTíN «tinerario de Pedro in Valladolid 1975; y S. DE $\mathrm{MOXO}, 0 . c$. págs. 33-42.

(27) La relación de proximidad no dejó de provocar en ocasiones situaciones conflictivas y recelos de una y otra parte. J. L. MARTíN, tratando de la escisión de las OO. Militares, habla de las «tierras de pastos situadas en el Sistema Ibérico y disputadas por la ganadería de Castilla y de Aragón» («La Península en la E. Media», 1976, pág. 671). J. VALDEÓN observa que «a lo largo de la zona montañosa del Sistema lbérico castellanos y aragoneses mantenían unas relaciones de vecindad difíciles. Amparados en las condiciones naturales eran frecuentes los asaltos de una y otra parte que consistían generalmente en el robo de ganados, aunque a veces también en la captura de rehenes" («Enrique II..." pág. 216).

(28) J. VINCKE «Documenta selecta mutuas Civitatis arago-cathalaunicae et Ecclesiae relationes illustrantia», Barcelona 1986, doc. 213, págs. 143-144. Pocos años antes (1306) D. Juan Manuel se había quejado al rey de que almogávares de Aragón habian robado en Buendía cuatro moros a su mayordomo mayor Juan Sánchez llevándolos a Albarracín y otras partes (G. SOLER, o.c., docs. CLV y CLVII, págs. 339-340).

(29) ACA, CR. Alfonso IV 1424. Ver F. DE MOXO «La relación epistolar Alfonso XI-Alfonso IV en el $A C A$ » en «En la España Medieval» III, Univ. Complutense 1982, págs. 173 ss.

(30) M. ALMAGRO, o.c., t. Ill pág. 216.

(31) ACA, R. 70, f. 27 r. ${ }^{\circ}$ Pocos años antes (1279) Pedro Ill había comisionado a Rey Ximénez de Luna, procurador del reino de Valencia, para la determinación de los límites con Castilla con el representante de Alfonso X. Ver nuestra tesis doctoral (en prensa) «La Casa de Luna (12761348)», Ap. docs. 30 y 9 (ACA, R. 41, f. 103 r. ${ }^{\circ}$ ).

(32) ACA, CR Alfonso IV 1656 (4 sept); R. 525 ff. 47v.-r. (16 nov.)

(33) ACA, R. 525 ff. 146v. - 147 r.v. $(24$ febr.)

(34) ACA, R. 530 ff. 192 v., 194 r.v. y 255 r.v.

(35) Zur. An. IV, 44.

(36) Crón. Sancho IV, C. VI, pág. 81.

(37) J. M. a SOLER, O.c., pág. 72.

(38) A. GUTIÉRREZ DE VELASCO «La guerra de los dos Pedros y la frontera castellanoaragonesa en el s. XIV" (Tesis doct. inédita) Madrid 1947; «La financiación aragonesa de la gue. rra de los dos Pedros» en «Hispania» LXXIV (1959); «Las fortalezas aragonesas ante la gran ofensiva

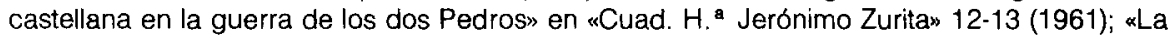
contraofensiva aragonesa en la guerra de los dos Pedros" en "CHJZ" 14-15 (1963); «Molina en la Corona de Aragón (1369-1375)» en «Teruel» 6 (1951), págs. 75-128.

(39) Zur. An. IX, 3. 
(40) J. SANZ y DIAZ «H. verdadera del señorío de Molina», pág. 122. G. DE VELASCO ( ¿La financiación..." pág. 4) resume asi el inicio de la contienda: «Difundido el pánico en las zonas de contacto, la gente abandona el campo y comienza el despoblamiento en masa de las tierras indefensas, retirándose ganados, víveres y enseres. Todo ello se traduce en un desastre para la economía agrícola y ganadera del país». Ariza, Aranda y Cetina quedaron pronto arruinadas por las incursiones guerreras (págs. 14-15).

(41) Zur. An. IX, 7.

(42) Zur. An. X, 5.

(43) Zur. An. X, 8.

(44) J. VALDEÓN «Enrique II...» pág. 215.

(45) Zur. An. X, 17.

(46) Zur. An. X, 19.

(47) ACA R. 1379, f. 170r.-v.; R. 1382 f. 76r.; G. DE VELASCO «La financiación...» págs. 25-26.

(48) Crón. Juan II, 1429, c. XXIV, pág. 462-463.

(49) Crón. Juan II, 1429, c. XXVII, pág. 464.

(50) Zur. An. XIX, 34.

(51) Crón. Juan II, 1429, c. XXXIV, pág. 467.

(52) Crón. Juan II, 1447, c. IV, págs. 654-655. Es interesante respecto a la complejidad demográfica de estos lugares fronterizos la observación de Zurita de que algunos de Verdejo eran castellanos y se alzaron por el rey de Castilla (An. XV, 51).

(53) Zur. An. XV, 56.

(54) Crón. Juan II, 1449, c. I, pág. 661.

(55) Zur. An. XVI, 5. En el capítulo siguiente añade Zurita los daños causados todavía en ese mismo año por la guerra contra el conde de Medinaceli y los suyos. 